NBER WORKING PAPER SERIES

THE HEALTH OF NATIONS:

THE CONTRIBUTION OF IMPROVED HEALTH TO LIVING STANDARDS

\author{
William D. Nordhaus \\ Working Paper 8818 \\ http://www.nber.org/papers/w8818 \\ NATIONAL BUREAU OF ECONOMIC RESEARCH \\ 1050 Massachusetts Avenue \\ Cambridge, MA 02138 \\ March 2002
}

The views expressed herein are those of the author and not necessarily those of the National Bureau of Economic Research.

(C) 2002 by William D. Nordhaus. All rights reserved. Short sections of text, not to exceed two paragraphs, may be quoted without explicit permission provided that full credit, including (C) notice, is given to the source. 
The Health of Nations: The Contribution of Improved Health to Living Standards

William D. Nordhaus

NBER Working Paper No. 8818

March 2002

JEL No. I1, N1, C82

\begin{abstract}
Nations generally measure their economic performance using the yardstick of national output and income. It is not widely recognized, however, that conventional measures of national income and output exclude the value of improvements in the health status of the population. The present study develops a methodology and presents preliminary estimates of how standard economic measures would change if they adequately reflected improvements in health status. The study first discusses the theory of the measurement of national income, examines some of the shortcomings of traditional concepts, and proposes a new concept called "health income" that can be used to incorporate improvements in health status. The study next discusses how the proposed measure fits into existing theories for measuring and valuing consumption and health status. The study applies the new concepts to data for the United States over the twentieth century and concludes that accounting for improvements in the health status would substantially increase the estimated improvement in economic welfare for the U.S. over the twentieth century.
\end{abstract}

William D. Nordhaus

Department of Economics

Yale University

New Haven, CT 06520-8264

and NBER

william.nordhaus@yale.edu 


\title{
The Health of Nations:
}

\section{The Contribution of Improved Health to Living Standards}

\author{
William D. Nordhaus, Yale University ${ }^{1}$ \\ January 25, 2002
}

\section{Introduction}

Nations generally measure their economic performance using the yardstick of national output and income. It is not widely recognized, however, that conventional approaches do a poor job of capturing improvements in the health of the population in our gross domestic product or incomes per capita. How would standard economic measures change if they adequately reflected improvements in the health status of the population as well as other goods and services? This is the question addressed in the present study.

The first section discusses the theory of the measurement of national income, examines some of the shortcomings of traditional concepts, and proposes a new concept that can be used to incorporate improvements in

1 The present research was supported in part by the National Science Foundation. I am grateful for comments from David Cutler, Angus Deaton, Robert Gordon, and T. N. Srinivasan. 
health status. In the second section, we discuss how the proposed measure fits into existing theories of consumption and valuation. The third section applies the concepts to the United States over the twentieth century.

At the end, we conclude that accounting for improvements in the health status of the population would make a substantial difference to our measures of economic welfare over the twentieth century in the United States.

\section{Including Health Status in Measures National Income}

Current Approaches to Measuring the Contribution of Health in the National Accounts

While the GDP and the rest of the National Income and Product Accounts (NIPA) may seem to be arcane concepts, they are truly among the great inventions of the twentieth century. Much as a satellite in space can survey the weather across an entire continent, so can the GDP give an overall picture of the state of the economy. Since their first construction by Simon Kuznets, who won the Nobel prize in Economics for his contributions to national income accounting, enormous strides have been taken in developing and improving indexes of economic welfare. Starting with rudimentary 
measures of national income and output, nations now have a wide range of indexes that not only include conventional concepts but also disaggregate these for industries and regions, use improved techniques for aggregation, and display a wealth of detail.

Nevertheless, since the beginning, there have been concerns that the accounts are incomplete and misleading because they omit most nonmarket activity. To meet this criticism, private scholars as well as official statistical agencies have begun extending the national accounts to include several nonmarket sectors, including national resources, the environment, transportation, leisure time, and unpaid work. ${ }^{2}$

One question that has been virtually ignored in attempts to extend the national accounts is the need to account adequately for improvements in human health. It is little understood outside the priesthood of national accountants that there is no serious attempt to measure the "real output" of the health-care industry. The techniques used to measure the price and quantity of

2 See Eisner [1989]. A recent review of environmental and other aspects of nonmarket accounting is contained in National Research Council [1999]. 
health care are highly defective, and there are no attempts to account for improvements in the length of life into current measures of living standards.

It might be argued that including health status is some radical, far-out, and woolly-headed attempt to incorporate intangible, non-economic, and sociological measures into our social accounts. This argument is wrong, for health-care expenditures are already included in measures of national income and output. Indeed they are a growing fraction of GDP - the fraction of personal consumption expenditures devoted to medical care rose from 5.1 percent in 1959 to 15.3 percent in 1998. What is radical is not the inclusion of health care but the notion advanced here that we should make a serious attempt to measure the output of the health care sector and to value this output correctly.

Both common sense and recent economic studies suggest that there is little connection between medical spending and the measured economic value of health-status improvements. At a common-sense level, the lack of connection comes because "real" medical-care spending in fact measures spending on inputs rather than the results in health outcomes. The current approach is to measure health output primarily by the number of physician- 
visits, the number of hospital-days, and similar measures rather than the actual delivery of services or changes in health status. It will come as a surprise to most non-economists that improvements that come from new products, such as the discovery of antibiotics or the substitution of drugs for invasive surgery, are completely omitted in current measures of real output.

Attempts to measure improvements in the health status of the population - including everything from vaccinations, microsurgery, and new drugs to airbags, exercise, and anti-cigarettes advertizing - pose a new and difficult challenge to measuring national income. Recently, economists have begun providing better outcome-oriented estimates of the prices and outputs in this sector. One of the most striking findings comes from a study by Cutler et al., who estimated that a true price index for the treatment of heart attacks would rise about 5.5 percent per year more slowly than the corresponding component of the CPI. ${ }^{3}$ Similar results were found in studies of treatment for glaucoma by Shapiro and Wilcox and for cataract surgery by Shapiro, Shapiro, and Wilcox. ${ }^{4}$

3 Cutler, McClellan, Newhouse, and Remler [1998]. 
Given the likelihood that we are dramatically mismeasuring, and almost certainly underestimating, the contribution of improvements in health care to economic welfare, this raises the question of how to proceed to obtain better estimates. One approach would be to continue the approach just described of constructing better measures of output and prices to reflect the (literal) decline in the cost of living. This approach was adopted by the Boskin Commission and is the thrust of much current research on health economics. ${ }^{5}$

Another quite different approach, which is used in the present study, is to obtain direct measures of health status, weight them with appropriate prices, and then estimate the value of improvements in health status. This approach treats medical care as an instrumental input and subtracts it from consumption expenditures. We would instead adjust real income to reflect the value of the improvement of health status. This approach is actually much simpler than "fixing" price and output indexes because measures of health status are generally much better than data on the impacts of particular technologies on health status. We will see that following this path has radical impacts on our measures of real income and output.

${ }^{4}$ See Shapiro and Wilcox [1997, 1999]. 


\section{Alternative Measures of National Income}

Before proposing alternative concepts, it will be useful to describe different approaches to measuring national income. The concepts of social income and national income go back centuries. They are largely based on the analogous definitions of individual income with appropriate adjustments for aggregation and national boundaries. We can distinguish two fundamentally different approaches to measuring income - one based on production and one based on utility. (Utility in this context means preferences, not usefulness.) The former is the basis of modern national-income accounting while the latter is more appropriate when considering sustainable income and the contribution of improvement in health status.

$\underline{\text { Production-based measures (Hicksian Income) }}$

5 See Advisory Commission [1996] and Murray and Lopez [1996]. 
The modern treatment of social income dates from the writings of J. R.

Hicks. When economists and accountants measure national income, they have almost universally rely upon the Hicksian definition. The discussion of social income in Value and Capital states, "The purpose of income calculations in practical affairs is to give people an indication of the amount which they can consume without impoverishing themselves." 6 Hicks then goes on to provide his first definition of social income:

Income No. 1 is thus the maximum amount which can be spent during a period if there is to be an expectation of maintaining intact the capital value of prospective returns...; it equals Consumption plus Capital

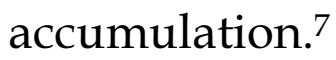

This definition is what is called "Hicksian income" - the maximum amount that can be consumed while leaving capital intact. In practice, this means that income equals consumption plus a generalized measure of capital accumulation.

${ }^{6}$ Hicks [1939], p. 172. 
The Hicksian concept is the standard definition of net national or domestic product used in the national-income accounts of virtually all nations today, where consumption and investment are limited to those legal goods and services that pass through the market place. It is production-based in the sense that it attempts to measure the rate of production at a given time. Such measures are not concerned with the health status of the population or whether people are enjoying that production for a longer period of time.

\section{Utility-based measures (Fisherian income)}

While standard concepts of income are useful tools for measuring current production, it is difficult to extract any welfare significance from them. The shortcoming of the traditional approach is clear when we consider situations where technologies are improving or where people are living longer. An economy in which people have a per capita income of $\$ 20,000$ with lives that are nasty, brutish, and short would be ranked as equivalent to one with the same per capita income and lives that are healthy, civilized, and long. In

7 Hicks [1939], p. 173, 178, emphasis added. This discussion ignores the subtlety of Hicks' discussion of price changes, interest rate effects, the difference between ex ante and ex 
the context of health, the key point is that the same annual income with a long and healthy live should be ranked as a higher living standard than that income with a short and diseased live. Including health status in income is particularly important when a large and growing fraction of our economy is devoted to health care.

An alternative approach is to define income as utility-equivalent consumption. ${ }^{8}$ I have called this "Fisherian income" after Irving Fisher, who defined income as the flow of consumption that could be harvested from the nation's capital stock. ${ }^{9}$ Under this approach, income is defined as the level of consumption that would give the equivalent level of utility from consumption and other determinants of utility in different situations. This definition has been used to define the level of "sustainable income" in situations where there is a tug-of-war between resource exhaustion and technological change. ${ }^{10} \mathrm{In}$ cases where lifetimes are fixed, this is equivalent to defining income as the consumption equivalent of current assets and current and future technologies.

post capital, and a number of other factors.

8 This approach is used in an analogous manner in the theory of measuring the cost of living.

9 See Nordhaus [1994, 1995] for a discussion.

10 See Nordhaus [1994]. 
For concreteness, call this "utility national income" and define it as follows:

Definition. Utility national income is the maximum amount that a nation can consume while ensuring that members of all future generations can have lifetime utility that is at least as high as that of the current generation.

If life expectancy in unchanging, income is the maximum real consumption annuity that a nation can spend out of its resource endowment. The major difference in analyzing living standards with variable lifetimes is to recognize that people are better off when they live longer, and that this fact should be reflected in measures of their incomes and living standards. This approach measures the increased income from longer life expectancies by the consumption-equivalent of the utility or value of the health or longevity improvements. 


\section{Integrating Health Status into Income Measures}

Consumption and income are traditionally measured as flows of goods and services (or utilities) during a given period of time. Changes in an individual's health status (while alive) pose no terribly deep issues of measurement, for we can treat these as new or improved "goods and services" which can be appropriately priced and included in the consumption basket.

Treatment of shortening or lengthening life, by contrast, poses qualitatively different problems of measurement. I begin this section by considering a simple life-cycle model of consumption in which there are tradeoffs between life and consumption. I then show how this approach might be used to construct a framework for measuring income.

\section{A. A Life-Cycle Model with Variable Lifetime}

We want to examine the gain in "real income" from improved health and life expectancy. We do this in the context of the life-cycle model of 
consumption. An individual is assumed to value consumption and health according to a lifetime utility function: ${ }^{11}$

(1) $V\left[c_{t} ; \theta, \rho, \mu_{t}\right]=\int_{\theta}^{\infty} u\left(c_{t}\right) e^{-\rho\left(t^{-\theta}\right)} S\left[\mu_{t}\right] d t$

Where $\mathrm{V}\left[\mathrm{c}_{\mathrm{t}} ; \theta, \rho, \mu_{\mathrm{t}}\right]$ is the value at time $\mathrm{t}$ of the consumption stream now and in the future faced by an individual of age $\theta$; $u\left(c_{\mathfrak{t}}\right)$ is the stream of instantaneous utility or felicity of consumption; $\rho$ is the pure rate of individual time preference; $\mathrm{S}\left[\mu_{\mathrm{t}}\right]$ is the set of survival probabilities; and $\mu_{\mathrm{t}}$ is the set of mortality rates. The key assumption here is that utility is a function of the expected value of consumption weighted by the probability of survival. As we will see, the utility function has a natural semi-cardinal interpretation as the value of life extension.

11 An early treatment of this issue is contained in Shepard and Zeckhauser [1984]. A detailed treatment of the value of life with extensions is contained in Rosen in Tolley et al. [1994]. 
We begin with a simple and tractable assumption about mortality to show the basic relationships; when developing the empirical estimates in later sections we will use more realistic life tables. Consider the simple case where the survival function is exponential. Equation (1) then becomes:

(2) $\mathrm{V}\left[\mathrm{c}_{\mathrm{t}} ; \theta, \rho, \mu_{\mathrm{t}}\right]=\int_{\theta}^{\infty} \mathrm{u}\left(\mathrm{c}_{\mathrm{t}}\right) \mathrm{e}^{-\left(\rho^{(\mu}\right)\left(\mathrm{t}^{-\theta}\right)} \mathrm{dt}$

We assume that each individual has a given endowment of expected labor income and can buy zero-cost real annuities that have any desired trajectory. We can further simplify for computational purposes (to be relaxed later) by assuming that the real interest rate faced by the individual is equal to the mortality adjusted rate of time preference, $(\rho+\mu)$. Given these assumptions, the individual will choose a consumption annuity that yields constant consumption during the individual's lifetime, $\mathrm{c}_{\mathrm{t}}=\mathrm{c}^{*}$. Integrating (2) yields a particularly simple outcome:

(3) $\mathrm{V}\left[\mathrm{c}_{\mathrm{t}} ; \theta, \rho, \mu\right]=\mathrm{u}\left(\mathrm{c}^{*}\right) /(\rho+\mu)$. 
Equation (3) shows that the total utility value of consumption is the utility of the flow of constant consumption discounted by a discount rate that equals the sum of the force of impatience and the force of mortality.

An individual will often face a tradeoff between "health and wealth." What would be the tradeoff given by (3)? At age $\theta$, changes in consumption and health yield:

$$
\mathrm{dV} / \mathrm{dc}^{*}=\mathrm{u}^{\prime}\left(\mathrm{c}^{*}\right) /(\rho+\mu)
$$

(4)

$$
\mathrm{dV} / \mathrm{d} \mu=-\mathrm{u}\left(\mathrm{c}^{*}\right) /(\rho+\mu)^{2}
$$

Hence the relative value of consumption and mortality is:

(5) $\quad \mathrm{dc}^{*} / \mathrm{d} \mu=-\mathrm{u}\left(\mathrm{c}^{*}\right) /\left[\mathrm{u}^{\prime}\left(\mathrm{c}^{*}\right)(\rho+\mu)\right]$

We make two normalizations that will simplify the discussion without loss of generality. First, we simplify by selected a goods-metric utility function. This gives us a metric in which utility is measured in terms of goods at the 
equilibrium, which implies that $\mathrm{u}^{\prime}\left(\mathrm{c}^{*}\right)=1$. In other words, $u$ tility is defined so that one unit of utility is one extra unit of the good. Second, we chose the units so that zero is the "death-indifference level of existence." That is, when the utility of consumption is $\mathrm{u}(\mathrm{c})=0$, the individual is indifferent between life and death. This implies that there is zero utility after death.

Given these assumption, (5) reduces to:

(6) $\mathrm{dc}^{*} / \mathrm{d} \mu=-\mathrm{u}\left(\mathrm{c}^{*}\right) /(\rho+\mu)$

or without discounting

(7) $\quad \mathrm{dc}^{*} / \mathrm{d} \mu=-\mathrm{Tu}\left(\mathrm{c}^{*}\right)$

where $T$ is life expectancy $(T=1 / \mu) . \quad$ The interpretation here is that a uniform change in mortality rates at every age will produce a welfare change equal to the number of years of life (T) times the goods value of life, given by $u\left(c^{*}\right)$ - recall that the utility of years after death is normalized at $u=0$.

The major difficulty in applying this approach is determining the goods value of life. There have been many studies of this, which are reviewed below. 
An example is as follows: Most studies of life value examine the tradeoff between current risk and current income, say at age $K=40$. Consider a decline in the mortality rate of $\Delta \mu(\theta)$ for one period. Then the survival rate is higher by $\left.\mathrm{e}^{\Delta \mu_{(} \theta}\right)$ at the end of the period, $K+1$. Discounted utility evaluated at age $\theta \geq K$ is then

(8) $\quad \mathrm{V}(\theta)=\mathrm{e}^{\Delta \mu}(\theta) \mathrm{u}\left(\mathrm{c}^{*}\right) /(\rho+\mu)$

Hence, using this simple mortality assumption, the tradeoff between current risk and current consumption is approximately:

(9) $\mathrm{dc} / \mathrm{d} \mu(\theta)=\mathrm{u}\left(\mathrm{c}^{*}\right)$.

Now the decline of $\Delta \mu(\theta)$ leads to a change in life expectancy of approximately $\Delta \mathrm{T}=\Delta \mu / \mu$. The value of this change is

$$
\mathrm{dV} / \mathrm{dT}=\mathrm{dV} / \mathrm{d} \mu(\theta) \mathrm{d} \mu(\theta) / \mathrm{dT} \sim \mathrm{u}\left(\mathrm{c}^{*}\right) \mu /(\rho+\mu)
$$

So the tradeoff between life expectancy and consumption is approximately:

(10) $\mathrm{dc} / \mathrm{dT}=\mathrm{u}\left(\mathrm{c}^{*}\right) \mu$ 
Note that this approach indicates that it is not generally correct to adjust for changes in health status by calculating lifetime consumption, which would be $c^{\star} \mathrm{T}$ in the present example. This approach is only correct when $\mathrm{u}(\mathrm{c})=1$. Our numerical estimates below indicate that this approach will generally undervalue improvements in life expectancy.

\section{B. Valuation of Life}

Measuring utility income with health improvement requires finding appropriate "prices" to use to value health status. There is a voluminous literature on the value of fatalities prevented..$^{12}$ It is generally accepted that the "willingness to pay" to reduce risk is the appropriate approach for valuing risk reductions. Studies of this fall into three general categories: labor market studies, which examine the risk-wage tradeoff; consumer purchase decisions (such as for smoke detectors), which examine the price-risk tradeoff; and 
contingent valuation studies, which attempt to determine preferences from a systematic examination of individual's stated preferences.

The most weight is generally put on labor market studies because these reflect actual behavior, because labor force decisions are repeated, and because there are dozens of studies from different periods, countries, occupations, and samples. It is important to note that the tradeoff examined is a current riskcurrent income $(\mathrm{dc} / \mathrm{d} \mu)$ choice between current occupational hazards and current wages. From these tradeoffs (which involve comparing income per year against mortality risk per year) we derive an implicit dollar cost per unit mortality risk. Because the risks are relatively small (around between $1 / 100,000$ per year to $50 / 100,000$ per year), the interpretation is the marginal valuation of risk reduction or increase.

Not surprisingly, there is great variation in the implicit price of risk (or price of a statistical life). The serious estimates from a recent survey range from $\$ 0.6$ million to $\$ 13.5$ million per fatality prevented. The U.S. Environmental Protection Agency use the relatively high figure of $\$ 4.8$ million per fatality

12 See Viscusi [1993] for a comprehensive review of the economics literature. The monumental study edited by Murray and Lopez [1996] is a particularly useful analysis of 
prevented in its cost-benefit study of the value of clear air. ${ }^{13}$ Tolley et al. recommend a value of $\$ 2.0$ million per fatality prevented for use in health-care decisions. ${ }^{14}$ In this study, I settle on $\$ 3.0$ million per fatality prevented as a reasonable choice, but the figures are easily modified to reflect different assumptions.

In our analysis above, we calculated the increment to sustainable consumption of an additional life-year, LY [see equation (10)]. There is some confusion but little solid evidence on how to measure the value of an added life-year. Most studies derive LY values from the studies of the value of reduced mortality described above.

We can sketch the methodology as follows. In terms of the model used above, almost all estimates concern the value of reductions in current mortality $[\operatorname{dc}(\theta) / d \mu(\theta)]$. For concreteness, we assume the following:

(11)

$$
\mathrm{dV} / \mathrm{d} \mu(\theta)=\$ 3 \times 10^{6}
$$

(in 1990 incomes and prices)

the issue in the context of health care.

13 This was based on the survey by Unsworth, Neumann, and Browne [1992]. 14 See Tolley et al. [1994]. 
To convert this to the value of a life-year requires further assumptions. Many of the studies underlying the estimate in (11) concern labor market decisions of working men, for which we can use $\mu(40) \sim 0.025 \mathrm{yr}^{-1}$ for those age 40 . To convert these into value per life-year requires assuming a discount rate, which we alternatively take to be 0 and 3 percent per year. Using these values, we obtain

$$
\$ 1,828 \text { per LY@ } \rho=0
$$

(12) $\mathrm{dc}^{*} /\left.\mathrm{dT}\right|_{\mathrm{d} \mu(40)}=\{$

$$
\$ 6,757 \text { per LY @ } \rho=0.03
$$

These are the annuity or flow equivalents of the present value of an increase in a LY. That is, they reflect the increase in the constant consumption necessary to compensate for a current loss of a life-year. Taking the present value of the consumption annuity yields a capital value $[\mathrm{dV} / \mathrm{dLY}]$ of $\$ 75,000$ per $\mathrm{LY}$ at a discount rate of 0 and $\$ 162,000$ per $\mathrm{LY}$ at a discount rate of 3 percent per year. Tolley et al. [1994] recommend a central present value of $\$ 100,000$ per LY from their studies, which is broadly consistent with these numbers and analysis. 
In the estimates presented below, we use actual survival functions rather than the theoretical ones analyzed above. Using 1990 life tables, we obtain the following estimates:

$$
\$ 2,600 \text { per LY at } \rho=0
$$

(12') $\mathrm{dc}^{*} /\left.\mathrm{dT}\right|_{\mathrm{d} \mu}=\{$

$$
\$ 7,600 \text { per LY at } \rho=0.03
$$

These estimates using actual life tables in (12') are quire close to the values for the simplified model given in (12), which motivates using that model. (The capital values associated with these numbers are given at the bottom of Table 2.)

\section{Measuring Income with Variable Lifetimes}

Next turn to the issue of measuring income or consumption. For this purpose, we take the utility-based measure of income. It will be helpful to start with the case of utility-based income with fixed and certain lifetime. In this approach income is the maximum sustainable consumption consistent with a 
given expected value of labor earnings and an exogenously given interest rate. Under the assumption of no bequests, note that income is also equal to sustainable consumption, where the latter is defined as the maximum constant real consumption annuity.

More precisely, assume that the consumption discount rate is a constant, r. Once we know the entire path of consumption, given by $\mathrm{C}(\mathrm{s})$ for $s \geq t$, we can easily calculate utility income at time $\mathrm{t}$, denoted by $\boldsymbol{C}(\mathrm{t})$, as follows:

(13) $\int_{\mathrm{t}}^{\infty} \boldsymbol{C}(\mathrm{t}) \exp [-\mathrm{r}(\mathrm{s}-\mathrm{t})] \mathrm{ds}=\int_{\mathrm{t}}^{\infty} \mathrm{C}(\mathrm{s}) \exp [-\mathrm{r}(\mathrm{s}-\mathrm{t})] \mathrm{ds}$

or equivalently

(14) $\quad \boldsymbol{C}(\mathrm{t})=\mathrm{r}\left[\int_{\mathrm{t}}^{\infty} \mathrm{C}(\mathrm{s}) \exp [-\mathrm{r}(\mathrm{s}-\mathrm{t})] \mathrm{ds}\right]$ 
Note that $\boldsymbol{C}(\mathrm{t})$ measures the constant consumption annuity available at time $\mathrm{t}$. Equation (14) shows that measures of utility income or sustainable income are inherently a wealth-like measure as was emphasized by Irving Fisher and Paul Samuelson. ${ }^{15}$

The utility definition of income is a natural springboard for considering the measurement of income with varying lifetimes. Begin by extending the definition of income and consumption to uncertain, variable, and endogenous lifetimes. To begin with, consider the traditional definition of income. For example, say that in lifetime situation "Short" individuals consume 100 units per year each and live for 50 years while in situation "Long" individuals consume 100 units per year and live for 60 years. Under the standard flow definition of consumption, there would be no difference in economic welfare or living standards between Short and Long. This is clearly defective to the extent that people prefer to live longer.

15 Irving Fisher's discussion dates from 1910 -14 and is contained in Fisher [1997]. Paul Samuelson's approach is contained in Samuelson [1961]. 
An alternative and preferable approach is to convert the combination of consumption and the survival function into the equivalent utility with a benchmark survival function and consumption. Take the Short lifetime situation as the benchmark. Using the example of the last paragraph, we ask what consumption annuity using the life expectancy of situation Short would give individuals the same utility as the consumption and life expectancy of situation Long. An individual might consider situation Long (with a constant consumption of 100 and a lifetime of 60 years) to be equivalent to, or have equivalent utility with, a constant consumption annuity of 110 units per year with the life expectancy of situation Short. We would then say that (using situation Short as the benchmark) the income in situation Long was 110 compared to that of 100 in situation Short.

Using the notation of the last section, define $\mathrm{S}=$ Short and $\mathrm{L}=$ Long. Then let $\mathrm{V}\left[\mathrm{ct}_{\mathrm{t}}^{\mathrm{S}} ; \theta, \rho, \mu_{\mathrm{t}}^{\mathrm{S}}\right]$ be the utility of consumption stream $\mathrm{c}_{t}^{\mathrm{S}}$ and agespecific mortality rate $\mu_{t}^{S}$ while $V\left[c_{t}^{L} ; \theta, \rho, \mu_{t}^{L}\right]$ is the utility of consumption stream $c_{t}^{L}$ and age-specific mortality rate $\mu_{t}{ }^{L}$. We define income $c^{*}\left(L, \mu^{S}\right)$ as the constant consumption stream that would go with mortality rates in Short which yields the equivalent utility as the consumption stream and mortality rates in situation Long. That is, $\mathrm{V}\left[c^{*}\left(\mathrm{~L}, \mu^{\mathrm{S}}\right) ; \theta, \rho, \mu_{\mathrm{t}}^{\mathrm{S}}\right]=\mathrm{V}\left[\mathrm{c}_{\mathrm{t}}^{\mathrm{L}} ; \theta, \rho, \mu_{\mathrm{t}^{\mathrm{L}}}^{\mathrm{L}}\right]$. 
We then compare incomes in different situations by estimating the constant equivalent consumption annuity with a benchmark mortality function. Say we use mortality rates from situation $S$ as the benchmark. We can then compare situations $S$ and $L$ by comparing $c^{*}\left(S, \mu^{S}\right)$ and $c^{*}\left(L, \mu^{S}\right)$, such that $\mathrm{V}\left[\mathrm{c}^{*}\left(\mathrm{~S}, \mu^{\mathrm{S}}\right) ; \theta, \rho, \mu_{\mathrm{t}}^{\mathrm{S}}\right]=\mathrm{V}\left[\mathrm{c}_{\mathrm{t}}^{\mathrm{S}} ; \theta, \rho, \mu_{\mathrm{t}}^{\mathrm{S}}\right]$ and $\mathrm{c}^{*}\left(\mathrm{~L}, \mu^{\mathrm{S}}\right)$ such that $\mathrm{V}\left[\mathrm{c}^{*}\left(\mathrm{~L}, \mu^{\mathrm{S}}\right) ; \theta, \rho\right.$, $\left.\mu_{t^{S}}{ }^{S}\right]=V\left[c_{t}^{L} ; \theta, \rho, \mu_{t}^{L}\right]$. There will be the usual index-number problems involved in these comparisons because the definitions will differ whether we use the mortality rates of situation $\mathrm{S}$ or L. It is to my knowledge an open question whether the usual index-number theorems apply here, but I see no reason why they should not.

Because this tangle of algebra is somewhat forbidding, it will be useful to summarize the major points. Traditional income accounting looks at the flows of consumption and income in measuring living standards - consumption of food, purchases of electricity and apparel, airline travel, and so forth. These measures do not consider the length of life or the quality of the population's health. The alternative proposed here corrects for mortality and morbidity by asking in effect how much consumption the individual would be willing to pay to trade off consumption for health. If, for example, an individual would 
pay two percent of consumption each year to gain an additional life-year, then we use that number to say that an additional life-year is equivalent to a two percent increase in annual income. In the estimates below, we use this technique only to adjust for changes in life expectancy, although they could also be used to adjust for changes in morbidity.

\section{The Impact of Improved Life Expectancy on Economic Welfare in the U.S., 1900- 1995}

\section{A. Previous Studies}

The literature on estimating the economic value of improved health is surprisingly sparse. Dan Usher considered the issue as part of a more general study of the adequacy of conventional national output measures, but his approach was highly stylized and was written before the surge of detailed estimates of the value of life. ${ }^{16} \mathrm{~A}$ number of indexes incorporate life expectancy, particularly the United Nations Development Program's Human Development Index (HDI). ${ }^{17}$ The technique for incorporating health in the HDI is, however, completely arbitrary. Economic historians have begun to compile

16 See Usher [1973] and 1980].

17 See UNDP [1997] for a discussion and the numbers. 
systematic indicators on various health-related measures, such as height and the body-mass index, and these tend to move with other measures of health status, but it is difficult to put a price tag on these indexes. ${ }^{18}$ Important additions to the literature are studies by David Cutler and Elizabeth Richardson, which is discussed below, and the contribution of Kevin Murphy and Robert Topel, presented at this conference. ${ }^{19}$

\section{B. Methods}

We now implement the ideas in earlier sections for the United States. The calculations here estimate the value of the health component of utility income, or the value of improvements in health status, which we call "health income." Table 1 shows illustrative data on major health risk in different regions from the study of the global burden of disease by Murray and Lopez [1996]. This table gives a rough idea of what economic development means in terms of health status.

18 A useful review of the economic-history literature is contained in Costa and Steckel [1995].

19 See Cutler and Richardson [1997] and Murphy and Topel [1999]. 
The fundamental data for the United States are shown in Figures 1 through 4. Figure 1 shows per capita consumption for the U.S. from 1900 to 1995. The data are from the Commerce Department for the period 1929-95 and from various private scholars for 1900-29. The Commerce Department figures are in chained indexes converted to 1990 price levels. Earlier estimates are in constant prices.

Figure 2 shows the survival rates for three years, 1900 1950, and 1995. The most dramatic change came in the early part of this century - the probability of surviving the first year rose from 87 percent in 1900 to 96 percent in 1950. Figure 3 shows life expectancy at different ages. Gains in life expectancy have been substantial throughout the entire century. Figure 4 shows the change in life expectancy at different ages over the last four decades.

One preliminary question concerns a parallel between health improvements and the slowdown in conventionally measured productivity. Is the famous "productivity slowdown" found in conventional economic measures mirrored in the health statistics? Figure 5 shows gains in life expectancy at birth along with conventionally measured growth in labor productivity for the decade ending in the year indicated by the point. "Health 
productivity growth" (measured as the change in life expectancy) rose until 1975 and then declined gradually since then. The trends in health and nonhealth productivity appear to move quite differently.

To calculate the value of improved health status, we use the approach outlined above. We use two different approaches - the mortality approach and the life-years approach. Under the mortality approach, shown for the simple model in equation (7), the value of improved health status is calculated by taking the change in the population weighted mortality rate times the estimated value of lower mortality. Under the life-years approach, shown in the simple model in equation (10), the economic value of improved health is equal to the increase in life expectancy times the value of an additional lifeyear. In both cases, the estimates are weighted by the share of the population that is experiencing the lower mortality or greater life expectancy.

\section{Simple calculations}

It may be helpful to work through a simple example to illustrate the methodology. For the period 1975 through 1995, the population-weighted average decline in the mortality rate was 2249 per year per million persons. 
Taking the hedonic estimate of the value of fatalities prevented of \$2.66 million (which adjusts the \$3 million in 1990 for movements in average consumption), this decline in mortality would have a value of $\$ 5,980$ per person over this period. The average per capita consumption over this period was $\$ 14,700$. Hence the economic value of improvements of living standards due to reduced mortality is estimated as 40 percent of consumption over this period, or about 2 percent per year. Table 2 shows this calculation using actual 1950 population weights, and the growth is 1.8 percent per year.

The estimate using the life-years method is somewhat more complicated. Because improvements in mortality extend life expectancy in the future (particularly in the case of reduced infant mortality), we must consider the impact of discounting on valuation. The approach taken for this simple example is to calculate the value of a life-year on the assumption that the increase in the life-year takes place through a uniform reduction in mortality. This allows us to use the valuation of mortality discussed above to estimate the value of an additional life year. For example, in 1990, a uniform reduction in mortality of 0.001 per year would lead to an increase in population-weighted life expectancy of 1.16 years. Over the period 1975-1995, the increase in population-weighted life expectancy was 2.1 years. The value of an additional 
undiscounted life-year is, according to the calculations presented above, equal to $\$ 2,600$ [see equation $\left(12^{\prime}\right)$ ]. Therefore the gain in health income over these two decades was $\$ 2,600 \times 2.1$ life-years $=\$ 5,400$. This is the equivalent of 1.6 percent per year in conventional consumption units. This is the close to the estimate shown by the actual calculations in Table 2 .

\section{Actual calculations}

The central results of this paper, showing calculations on the economic contribution of health and non-health consumption, are shown in Table 2 and in Figure 6. For these estimates, we use only changes in life expectancy and omit any changes in morbidity (we discuss this question below). These estimates differ from the simple calculations in the last section because they use actual survival rates and population distributions rather than the simplified ones assumed above.

The major result that comes through using all techniques is that the value of improvements in life expectancy improvements is about as large as the value of all other consumption goods and services put together. For example, over the two decades from 1975 to 1995, conventionally measured per capita 
consumption grew at an average rate of 2.0 percent per year. Over this period, the annual average improvements in life expectancy had an economic value between 1.6 and 2.0 percent of consumption. ${ }^{20}$ Over the entire period from 1900 to 1995, the value of improved health or health income grew at between 2.2 and 3.0 percent of consumption whereas consumption grew at a rate of about 2.1 percent of consumption. Health income grew somewhat more slowly than other consumption during the second half of this century while it exceeded the value of the growth in consumption during the first half of the $20^{\text {th }}$ century.

The two techniques (the life-year approach and the mortality approach) give approximately the same results. This is not surprising, for they are calibrated to yield the same value of life lengthening for uniform mortality rate changes. The mortality approach gives slightly larger numbers because of the distribution of mortality changes.

20 Because there is no natural denominator for measuring improvements in health care, we use the same denominator for calculating growth as we do for consumption. That is, the growth in the value of health is calculated as $\Delta \mathrm{YH}_{\mathrm{t}} / \mathrm{c}_{\mathrm{t}-1}$ whereas the growth in consumption is calculated as $\Delta \mathrm{c}_{\mathrm{t}} / \mathrm{c}_{\mathrm{t}-1}$, where $\Delta \mathrm{YH}_{\mathrm{t}}$ is the change in the per capita value of health income and $c_{t}$ is the flow of consumption of goods and services during the previous period. This allows us to compare the relative importance of consumption and improvements in health status, whereas there is no obvious way to measure the value of the level of health status $\left(\mathrm{YH}_{\mathrm{t}}\right)$. 
How do expenditures on health improvements compare with improvements in health income? This is a difficult question because spending to improve health status pervades our market and non-market activities. Table 3 provides illustrative estimates of the magnitudes. To begin with, the bottom three rows of Table 3 show the increase in non-health consumption and in health income over the 1980-90 period. This shows again that the size of the gains from health and non-health consumption are approximately the same.

Market expenditures on conventional health care are reasonably well tabulated. They were in 1990 about one-quarter of non-health personal consumption expenditures. Many important items are excluded from these figures. Two exclusions, shown in Table 3, are pollution abatement and expenditures on sewage and sanitation. In addition, there may be substantial non-market costs, primarily in time use. Our time-use studies are particularly inadequate, but existing estimates indicate that the value non-market time devoted to health is but a small fraction of market costs.

The last column of Table 3 compares the increases in expenditures with the increases in health income and non-health consumption for the period 
1980-90. These show that the increase in health income (from mortality alone) is approximately the same size as the increase in non-health consumption. The increase in expenditure on health care was approximately one-half the increase in mortality-based health income. It seems likely, however, that a substantial part of the expenditures (such as that on dental, psychiatric, vision-related, and nursing home) was life-quality-enhancing rather than life-year-extending.

Suppose that half of the per capita of increased expenditures, or $\$ 600$, was lifeextending; this would be a good investment for the increase in health income of between $\$ 2,300$ and $\$ 3,100$ per capita over the $1980-90$ period.

\section{E. Qualifications}

How robust are the estimates provided here? The underlying mortality data are among the most reliable of our social statistics. The most fragile part of the estimates concerns life and mortality valuation, as discussed above. One assumption on which there is little evidence is that the premium on reduced mortality is a constant fraction of per capita consumption over the entire period. More precisely, we assume that the value of a reduction in the mortality rate of 0.001 per year is $\$ 3$ thousand in 1990 prices and we scale that value over time to the ratio of the given year's per capita consumption to 1990 
per capita consumption. There are no comprehensive studies of the mortality premium over time, although movements in the wage of risky occupations (such as coal mining) are consistent with this assumption. I suspect, however, that the premium has risen over time. This would be consistent with the rising share of health care expenditures in total consumption. If the premium were indeed increasing over time, then the contribution of health to economic welfare would be relatively smaller in the earlier period and relatively larger in the later period.

A few other assumptions are of some significance but will not affect the major results. One important issue is whether people should be weighted the same at every age. Many health-care professionals and some survey evidence suggest that the value of a life-year is higher in the middle of the life span (between 20 and 40 years) than at either end. ${ }^{21}$ Most surveys indicate, for example, that infant mortality would receive a lower weight than adult mortality. Figure 7 shows an alternative set of weights proposed by Murray which differ by age. Figures 8 and 9 show the trend and changes in weighted and unweighted life expectancy for different discount rates. The weighted series show virtually identical growth as the equally weighted series over the 
period 1900-50 but have slower growth in income in the 1950-95 period. In the latter period, the growth in health income is between 10 and 20 percent slower with differential age weights, primarily because the Murray weights put a lower value on the increases in life expectancy of older people. Under this alternative valuation approach, the contribution of improved longevity would be slightly less than that shown in Table 2 .

Another major omission from this study is the value of reduced morbidity. The data on morbidity is both more difficult to obtain and more difficult to value. Recent studies indicate that including morbidity might add another 5 percent or so to the value of health improvements estimates here. ${ }^{22}$

\section{Discussion and Conclusion}

This paper contributes to a new view of the economics of health. This new view is that improvements in health status have been a major contributor to economic welfare over the twentieth century. To a first approximation, the economic value of increases in longevity in the last hundred years is about as

21 A particularly interesting discussion is contained in Murray and Lopez [1996]. 22 See Cutler and Richardson [1997], discussed below. 
large as the value of measured growth in non-health goods and services. A closer look shows that "health income" probably contributed somewhat more than non-health goods and services in the first half of the $20^{\text {th }}$ century and marginally less than non-health goods and services since 1950. The medical revolution over the last century appears to qualify, at least from an economic point of view, for Samuel Johnson's accolade as "the greatest benefit to mankind."

The first question one should ask is whether this finding is plausible. One way of considering the question is to consider the health equivalent of the Sears-catalogue question:

Consider the improvements to both health and non-health technologies over the last half century (say from 1948 to 1998). Health technologies include a variety of changes such as the Salk polio vaccine, new pharmaceuticals, joint replacement, improved sanitation, improved automobile safety, smoke-free workplaces, etc. Over this period, life expectancy at birth increased from a little above 68 year to a little less than 76 years. Non-health technologies were also wide-ranging and include the jet plane, television, superhighways, VCRs, and computers 
(although the economic benefits of these are probably understated in measured consumption growth).

Now consider the following choice. You must forgo either the health improvements over the last half-century or the non-health improvements. That is, you must choose either (a) 1948 health conditions and 1998 non-health living standards or (b) 1998 health conditions and 1948 non-health living standards. Which would you choose?

If you would either choose (b) or find it a difficult choice, then you would basically agree with the results of this paper. An informal poll finds most people who either choose (b) or have great difficulty choosing, with older people almost always opting for (b).

A recent study by Cutler and Richardson, which examines the improvements in "health capital" in the U.S., are consistent with the new view put forth above. ${ }^{23}$ Health capital is the present value of the utility of health status. Cutler and Richardson use both a years of life (YOL) approach and a quality adjusted years of life (QALY) approach. Their estimates are only for the years 1970, 1980, and 1990 and they present results only for persons of age 0 and 65. We can make a crude conversion of the Cutler-Richardson estimates to 
conform to our income estimates by annuitizing their health capital over the expected lifetimes and then taking the changes in the income from health capital as the increase in health income. Table 4 shows the comparison. Two points should be drawn from this table. First, the overall estimates are reasonably comparable. The estimates from Cutler and Richardson bracket the estimates from the present study. One of the most surprising results of CutlerRichardson, not explained in the paper, is that moving from life-years to QALYs does not change the results significantly. One possible reason for this result is that improvements in the quality of life from lower morbidity are offset by a higher average age (and therefore higher average morbidity) of the population.

There are many questions left open by the present findings. One important point is that we cannot at this stage attribute the growth in health income to particular investments or expenditures. Such a task, which would apply the techniques of growth accounting to health improvements, is especially challenging. ${ }^{24}$ It is also necessary if we are to understand not only

23 See Cutler and Richardson [1997].

24One of the most comprehensive studies of growth accounting is Denison [1961]. 
the historical sources of improved health but also those investments that may best contribute to future improvements.

Another particularly important question is the extent to which improvements arise from improved basic knowledge (such as the germ theory of disease, the discovery of antibiotics, or the DNA revolution ) or investments in improved health capital and infrastructure (such as larger investments in health education or improvements in emergency response services). A second issue, particularly relevant for the contribution of basic knowledge, is the extent to which improvements in knowledge were domestically generated or imported. It seems likely, for example, that most of the major medical discoveries in the first part of the period covered here arose in Europe, while America was increasingly the source of increases in medical knowledge in the last few decades. ${ }^{25}$ To the extent that improvements in health income are due to imported technologies, this emphasizes one of the gains from trade that is largely overlooked in traditional measures of the economic impacts of international trade.

25A non-technical history is contained in Porter [1997]. 
The new view of health economics should shape the way we think about health policy. In the early 1990s, the general hysteria about rising health costs led many to believe that the health-care system was wasteful, out of control, and should be reined in. This view was particularly prevalent in the business community, which saw rising health costs as a threat to national competitiveness. The general atmosphere was colored by the substantial rise in (measured) relative medical-care prices. Over the period from 1975 to 1995, the CPI for medical care rose 64 percent faster than CPI for all goods and services. In the face of rising prices and growing budgets, a natural response was to try to control spending and limit services.

If the results of this and other related papers are confirmed, then the role of the health-care system should be rethought. Over the last half century, economic welfare from health care expenditures appears to have contributed as much to economic welfare as the rest of consumption expenditures. It is an intriguing thought to contemplate that the social productivity of health-care spending might be many times that of other spending. If this is anywhere near the case, it would suggest that the image of a stupendously wasteful healthcare system is far off the mark. 
Of course, as Table 3 suggests, health is more than doctors and hospitals. It encompasses other parts of national output, such as pollution control and highway safety spending, and reflects individual lifestyles, such as decisions about smoking, drinking, driving, drugs, and exercise. Moreover, medical knowledge is a global public good which is increased by efforts in many countries. Because we cannot tally the totality of costs on health care, we cannot say for sure whether we are getting 2 or 4 or 10 times the return on health dollars that we are on non-health dollars. And it is surely the case that health-care expenditures are often misallocated and wasteful. However, notwithstanding the complexity and bureaucracy, improvements in health status in the U.S. have yielded prodigious increases in economic welfare. It is sobering to reflect that, were the author of this paper to have experienced the 1900 life table, the odds are long that this paper would have been written from beyond the grave. 


\section{References}

Advisory Commission [1996]. Boskin, Michael, et al., "Toward a More Accurate Measure of the Cost of Living: The Final Report of the Advisory Commission to Study the Consumer Price Index," December 4, (updated version).

Costa, Dora L. and Richard H. Steckel [1995]. “Long-term Health Trends in Health, Welfare, and Economic Growth in the United States," NBER Historical Working Paper 76, Cambridge, Massachusetts, National Bureau of Economic Research.

Cutler, David and Elizabeth Richardson [1997]. "Measuring the Health of the U.S. Population," Brookings Papers on Economic Activity: Microeconomics, pp. 217-271.

Cutler, David, Mark B. McClellan, Joseph Newhouse, and Dahlia Remler [1996]. “Are Medical Care Prices Declining?" NBER Working Paper 5750, Cambridge, Massachusetts, National Bureau of Economic Research, September.

Denison, Edward [1961]. The Sources of Economic Growth in the United States, Committee for Economic Development, New York.

Eisner, Robert [1989]. The Total Incomes System of Accounts, Chicago, University of Chicago Press.

Hicks, J.R. ]1939]. Value and Capital, Second Edition, Oxford: Clarendon Press.

Murray, Christopher J. L. Murray and Alan D. Lopez, editors [1996]. The Global Burden of Disease, Harvard School of Public Health, distributed by Harvard University Press, Cambridge, Mass.

National Research Council [1999]. Nature's Numbers : Expanding the National Economic Accounts to Include the Environment, William D. Nordhaus and Edward Kokkelenberg, Eds., National Academy Press, Washington, D.C.

Nordhaus, William D. [1994]. "Reflections on the Concept of Sustainable Economic Growth," in Economic Growth and the Structure of Long-Term Development, Luigi L. Pasinetti and Robert M. Solow, eds., Oxford University Press, 1994, pp. 309-325. 
Nordhaus, William D. [1995]. “How Can We Measure Sustainable Income?" Cowles Foundation Discussion Paper, May.

Porter, Roy [1997]. The Greatest Benefit to Mankind: A Medical History of Humanity, W.W. Norton, New York.

Robinson, John P. and Geoffrey Godbey [1997]. Time for Life: The Surprising Ways Americans Use Their Time, Pennsylvania State University Press, University Park, Pennsylvania.

Samuelson, Paul A. [1961]. “The Evaluation of 'Social Income,'” in F. A. Lutz and D. C. Haig, eds., The Theory of Capital, London, Macmillan.

Shapiro, Matthew and David Wilcox [1997]. "Mismeasurement in Consumer Price Index: An Evaluation," Macroeconomics Annual, vol. 11, pp. 93-142.

Shapiro, Irving, Matthew Shapiro, and David Wilcox [1998]. "Measuring the Value of Cataract Surgery," in E. Berndt and D. Cutler, eds., Medical Care, Output, and Productivity, NBER/CRIW conference, 1998.

Shepard, Donald S. and Richard J. Zeckhauser [1984]. "Survival versus Consumption," Management Science, vol. 30, no. 4, April, pp. 423-439.

Tolley, George S., Donald Scott Kenkel, and Robert Fabian, eds. [1994]. Valuing Health for Policy, University of Chicago Press, Chicago, Illinois.

Viscusi, W. Kip [1993]. "The Value of Risks to Health and Life," Journal of Economic Literature, vol. 31, pp. 1912-46.

Works of Irving Fisher [1997]. William J. Barber, ed., The Works of Irving Fisher, Pickering and Chatto, London.

UNDP [1997]. United Nations Development Programme, Human Development Report, 1997, Oxford University Press, New York.

Unsworth, Robert, James Neumann, and W. Eric Browne [1992]. "Review of Existing Value of Life Estimates: Valuation Document," Background Document Prepared for Section 812 Analysis, Industrial Economics Incorporated, Cambridge, Mass., November 6. 
Usher, Dan [1973]. “An Imputation to the Measurement of Economic Growth for Changes in Life Expectancy," in Milton Moss, ed., The Measurement of Economic and Social Performance, Columbia University Press, New York, pp. 193-226.

Usher, Dan [1980]. The Measurement of Economic Growth, Columbia University Press, New York. 


\section{Table 1. Major Health Risk Factors in Different Regions, 1990}

\section{Risk Factor}

Malnutriton

Poor water supply, santiation, and personal and domestic hygiene

Unsafe sex

Tobacco

Alcohol

Occupation

Hypertension

Physical inactivity

Illicit drugs

Air pollution

TOTAL

\begin{tabular}{cr}
\multicolumn{2}{c}{ Global Totals } \\
$\begin{array}{c}\text { Years of } \\
\text { Life Lost } \\
\text { (000) }\end{array}$ & $\begin{array}{l}\text { Percent } \\
\text { of Total } \\
\text { (percent) }\end{array}$ \\
199,486 & 22.0
\end{tabular}

85,520

27,602

26,217

19,287

22,493

17,665

11,353

2,634

5,625

417,882

46.0

0.6

Established Market Economies

Years of

Life Lost

(000)

0

Percent

of Total

(percent)

0.0

0.0

2.6

16.0

5.1

2,537

2,826

3,471

3,860

717

310

22,967

0.6

46.2

$$
5.7
$$

7.0

7.8

1.4

Source: Murray and Lopez [1996], vol 1, pp. 311-315.

796

449

377

0.7

Sub-sahran Africa

Years of Percent Life Lost of Total (000) (percent)

$89,305 \quad 39.4$

$28,781 \quad 12.7$

$12,226 \quad 5.4$

$927 \quad 0.4$

$3,319 \quad 5.9$

$1,973 \quad 3.5$

$1,674 \quad 3.0$

$796 \quad 1.4$

0.8

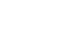

139,827

73.2 
Table 2

Growth in Living Standards from Health Improvements and Consumption

[Increase as percent of per capita consumption; in annualized percentage growth rates]

$1900-1925 \quad 1925-1950 \quad 1950-1975 \quad 1975-1995$

Consumption

Health Value: Life-years approach

Discount rate

0 percent p. a. 2.3

3 percent p. a. 2.3
2.0

1.8

2.4

2.0

3.3

3.2

1.9

1.7

1.8

1.6

Health Value: Mortality Approach

$\begin{array}{lllll}\text { Current pop. weights } & 3.2 & 4.0 & 2.6 & 2.0 \\ 1950 \text { weights } & 2.9 & 4.2 & 2.3 & 1.8\end{array}$

otes on valuation:

Value of Lite: (1990)

Value of Life year (1990)

rho $=0.00$

rho $=0.03$

Consumption (1990)
3000.0 thousand 1990 dollars

14.5 thousand 1990 dollars

95.3 thousand 1990 dollars

16.5 thousand 1990 dollars 
Table 3

\section{National Health Expenditures and Income, 1980-90}

[Per capita in 1990 prices and incomes]

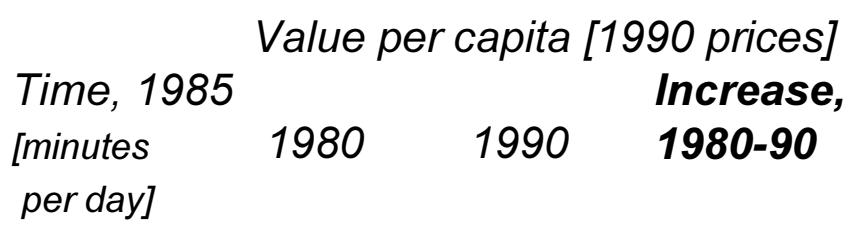

\section{Total Expenditures}

Market [a]

Conventional Health Care

Other

Pollution abatement

Sanitation and sewage
$2,477 \quad 3,690$

1,213

1,856

3,004

1,148

378

404

26

$99 \quad 123$

Nonmarket

Time spent on medical care $[b, c]$

Child care: medical

$1.0 \quad 32$

32

0

Obtaining Goods and services:

medical appointments

$2.0 \quad 64$

80

16

Personal needs: medical care

48

48

0

\section{Income and Consumption}

Health income, life-year method

Life-year method [d]

Mortality method [e]

Non-health personal consumption na

na

12,261

15,198

na

$2,292 \quad 1.7 \%$

$3,120 \quad 2.3 \%$

$2,937 \quad 2.2 \%$

[a] Current dollar figures are converted into 1990 prices using the price index for personal consumption. [b] Time is converted into current prices using average hourly earnings in 1990 less a tax rate of $30 \%$. [c] From Robinson and Godbey [1997], Appendix A.

[d] Uses the life-year method with a discount rate of 3 percent.

[e] Current population weights 
Table 4

\section{Comparison of This Study with Cutler-Richardson}

[Increase in health income per person, 1970-1990, 1990 prices and incomes]

\section{This study}

\section{Discount rate}

\section{0 percent per year 3 percent per yea}

Health Value: Life-years approach

Health Value: Mortality Approach
6,166

7,701
5,769

7,701

\section{Cutler-Richardson}

Years of Life

Age 0

Age 65

5,514

2,526

15,000

12,289

Quality Adjusted Life Years

Age 0

5,230

3,117

Age 65

15,438

13,062

Note: "Health income" is defined as the annuitized value of the increase in health capital for Cutler-Richardson study and as the increase in the value of population-weighted mortality or life expectancy in this study.

Source: This study from Table 1. Cutler and Richardson [1997] is from their Table 11.

The estimates have been annuitized over the life expectancy at the given age and at the given discount rate. 
Figure 1.

\section{Per capita consumption}

[1990 chained dollars]

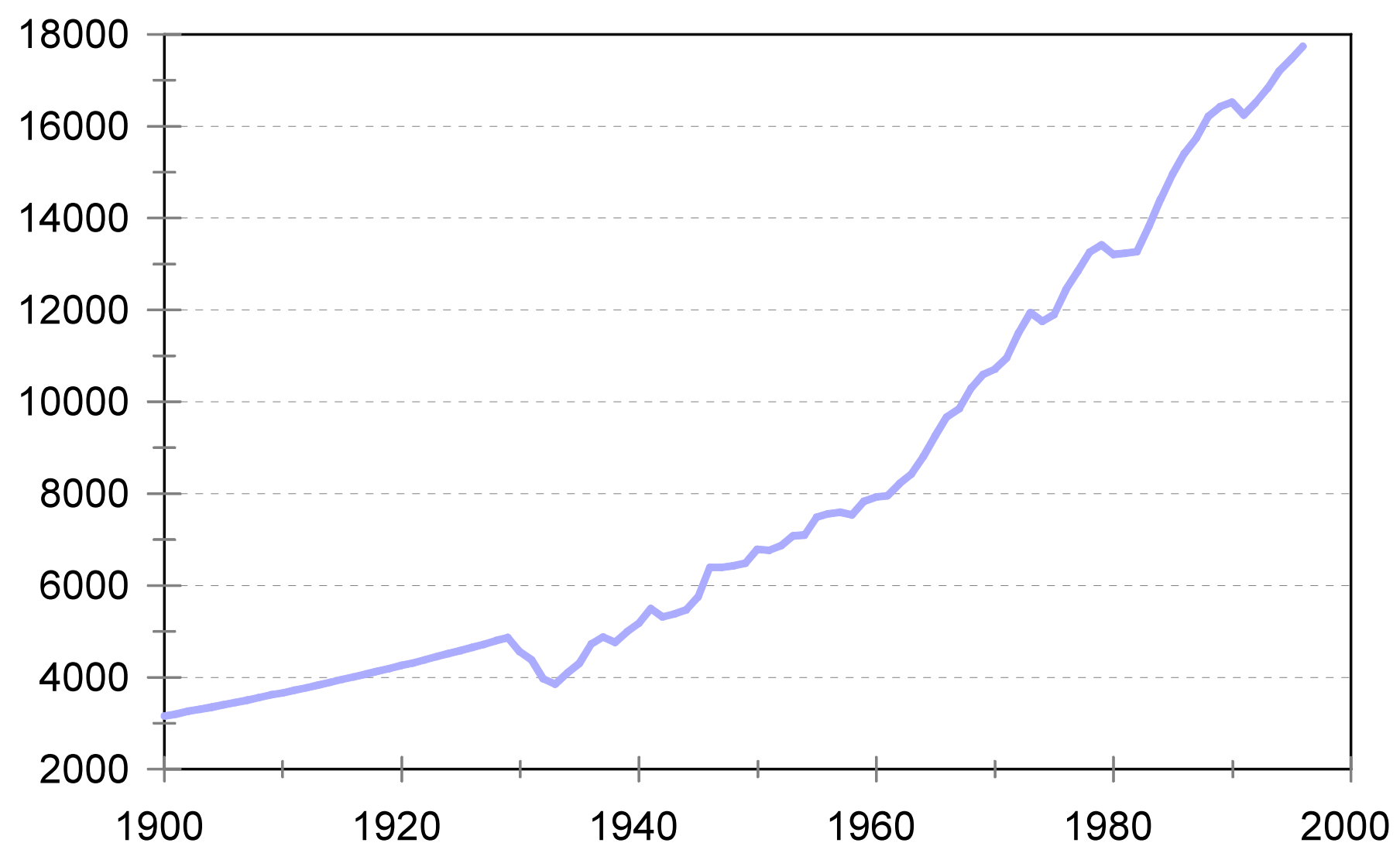


Figure 2

Survival Probabilities

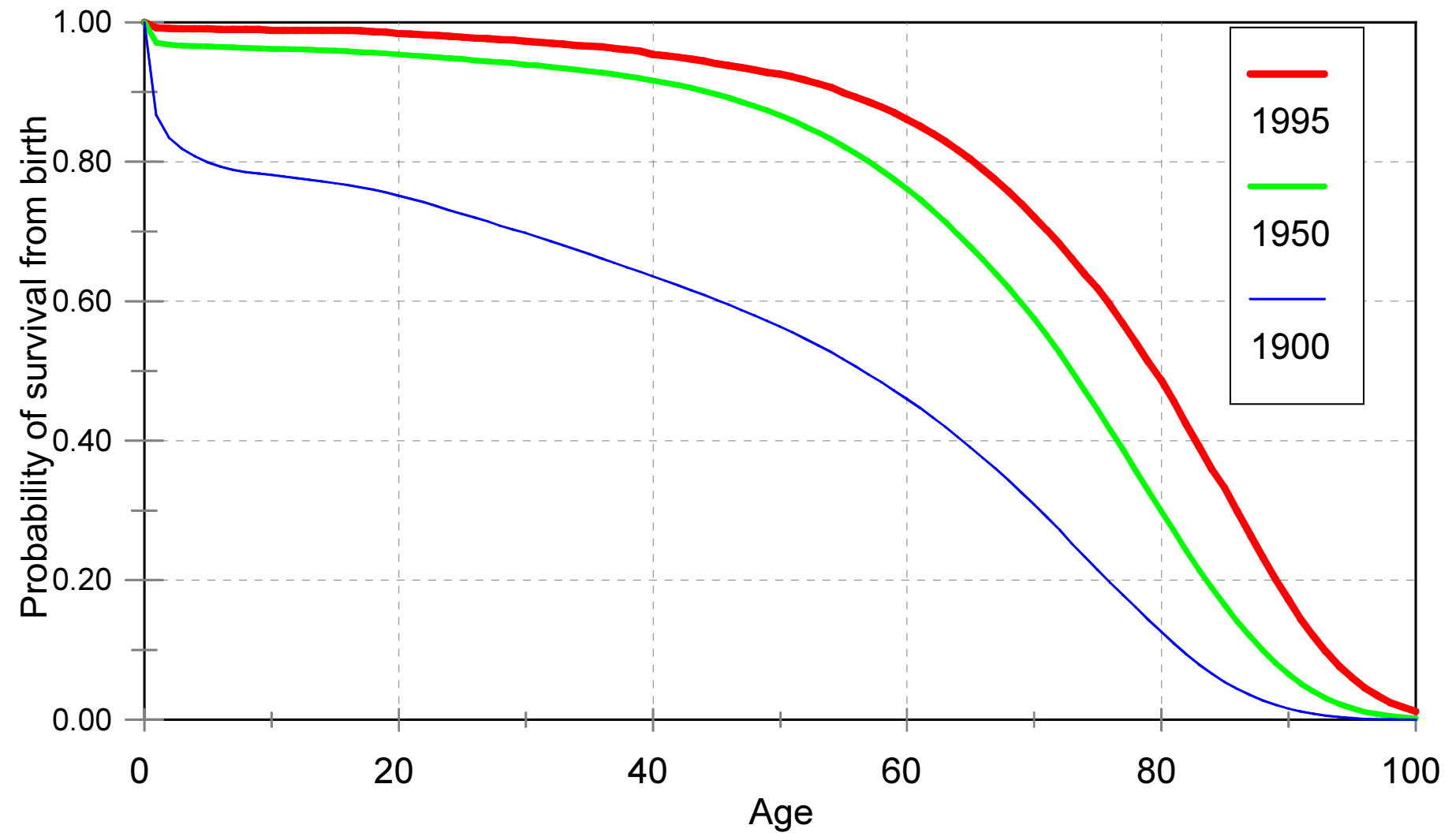


Figure 3

\section{Life Expectancy}

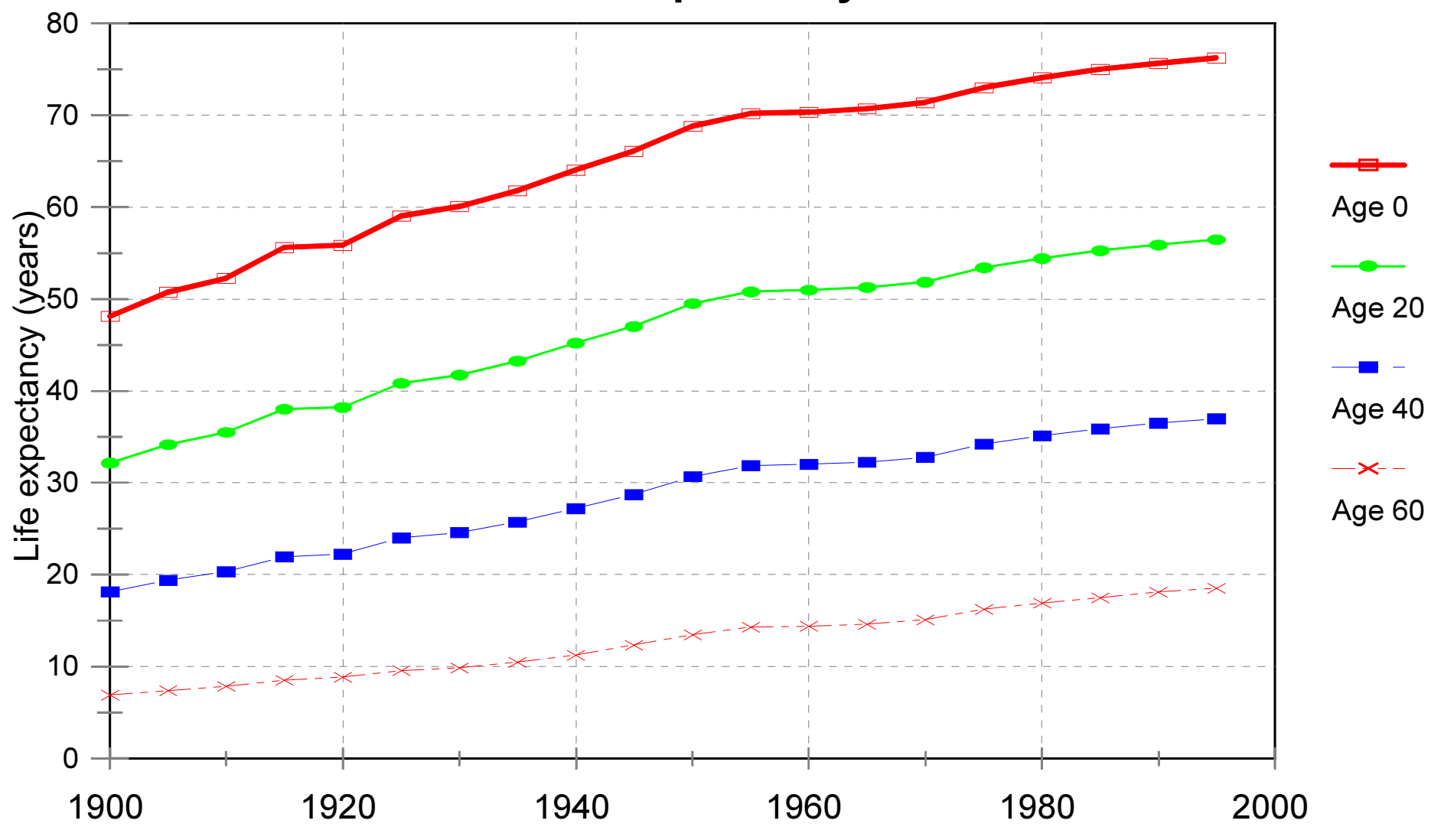


Figure 4

\section{Gains in Life Expectancy}

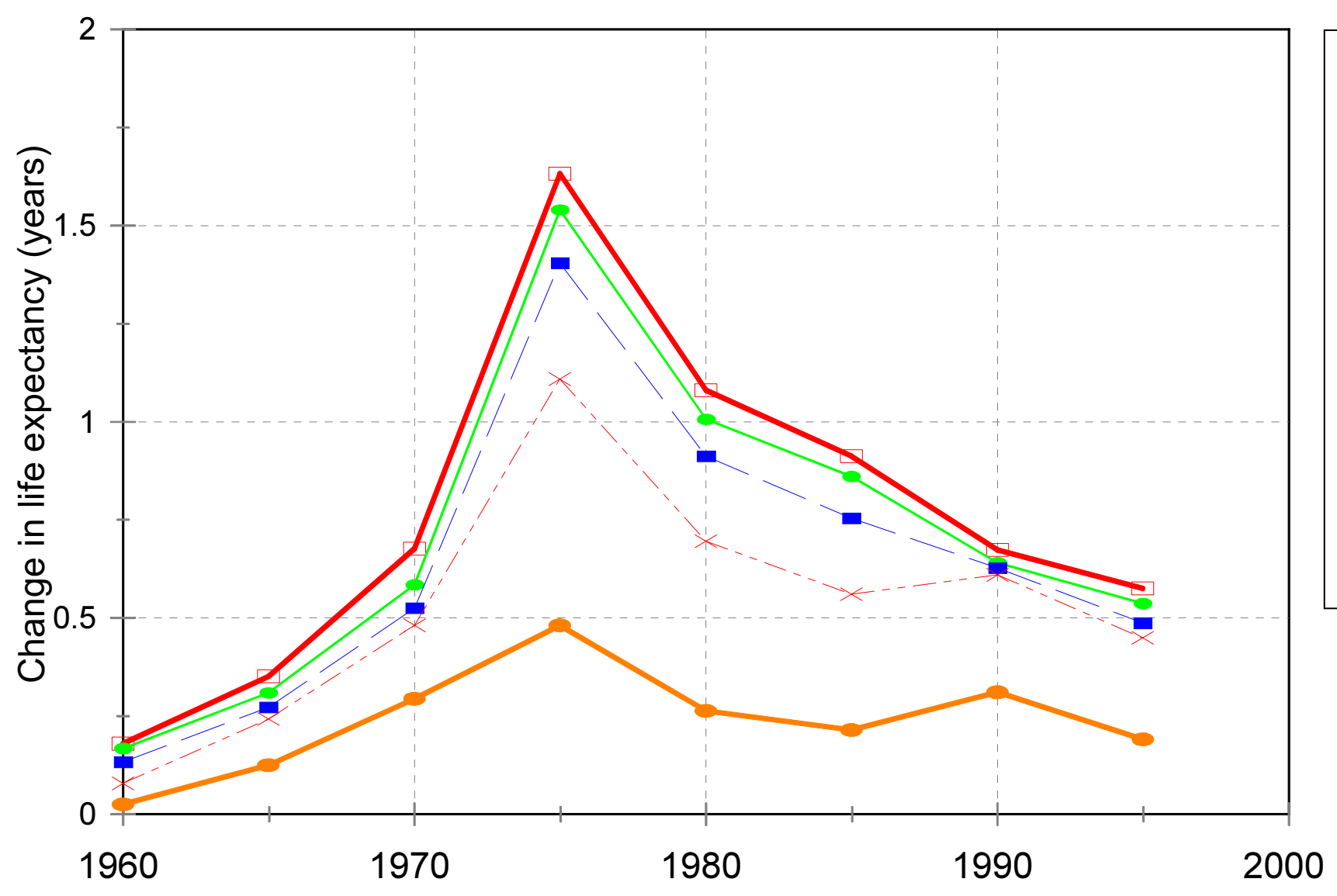


Figure 5

\section{Productivity and LE Growth}

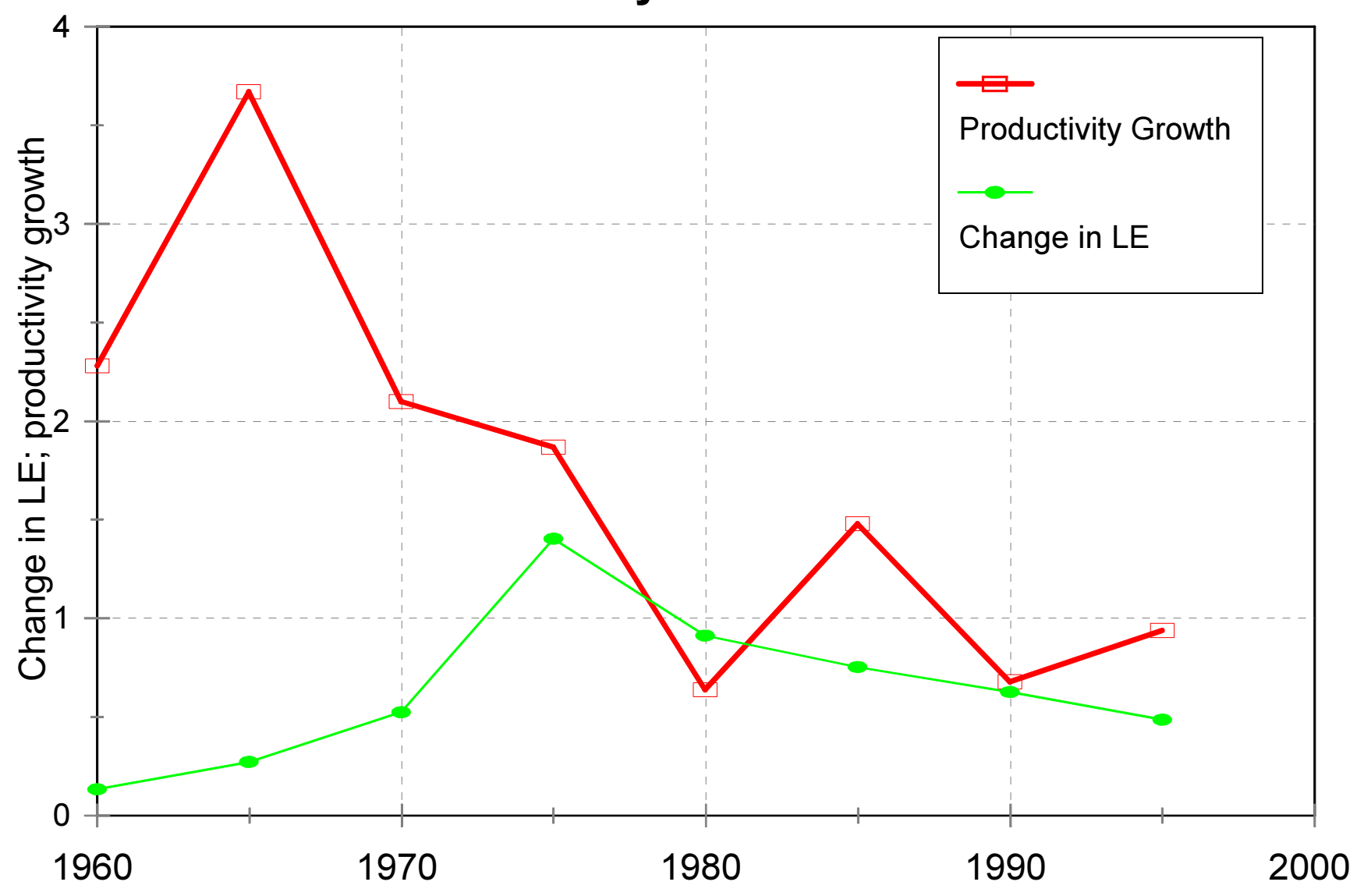


Figure 6

\section{Economic Contribution:}

Consumption and Health Status

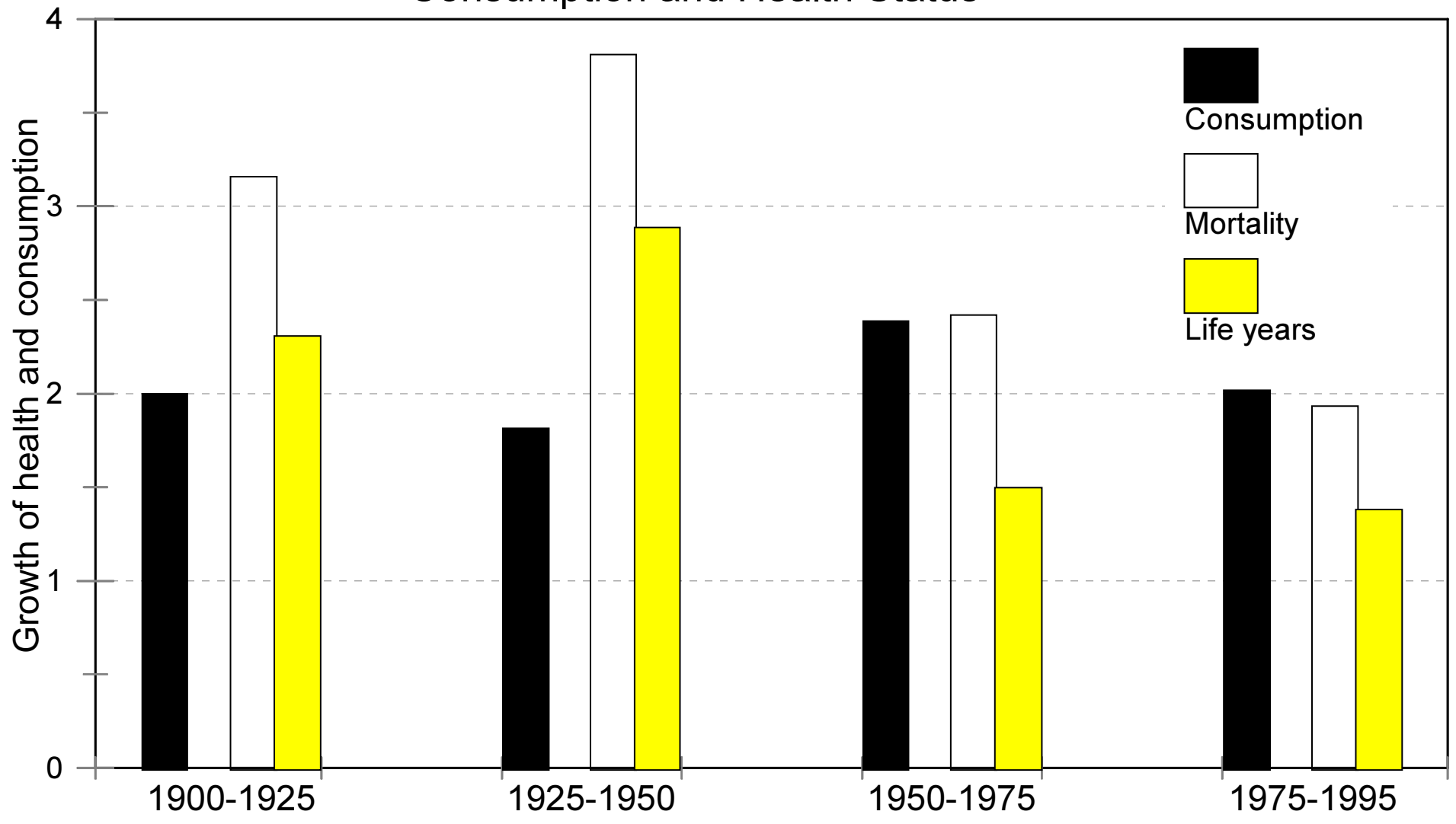

Note: Bars show the increase in either conventionally measured per capita consumption and in per capita "health income" for the period. In each case, the denominator used in calculating the growth rate is the level of conventionally measured per capita consumption. The figures are averages of for five-year periods. The two right bars use the mortality approach and the life-years approach to valuing increases in longevity. 
Figure 7

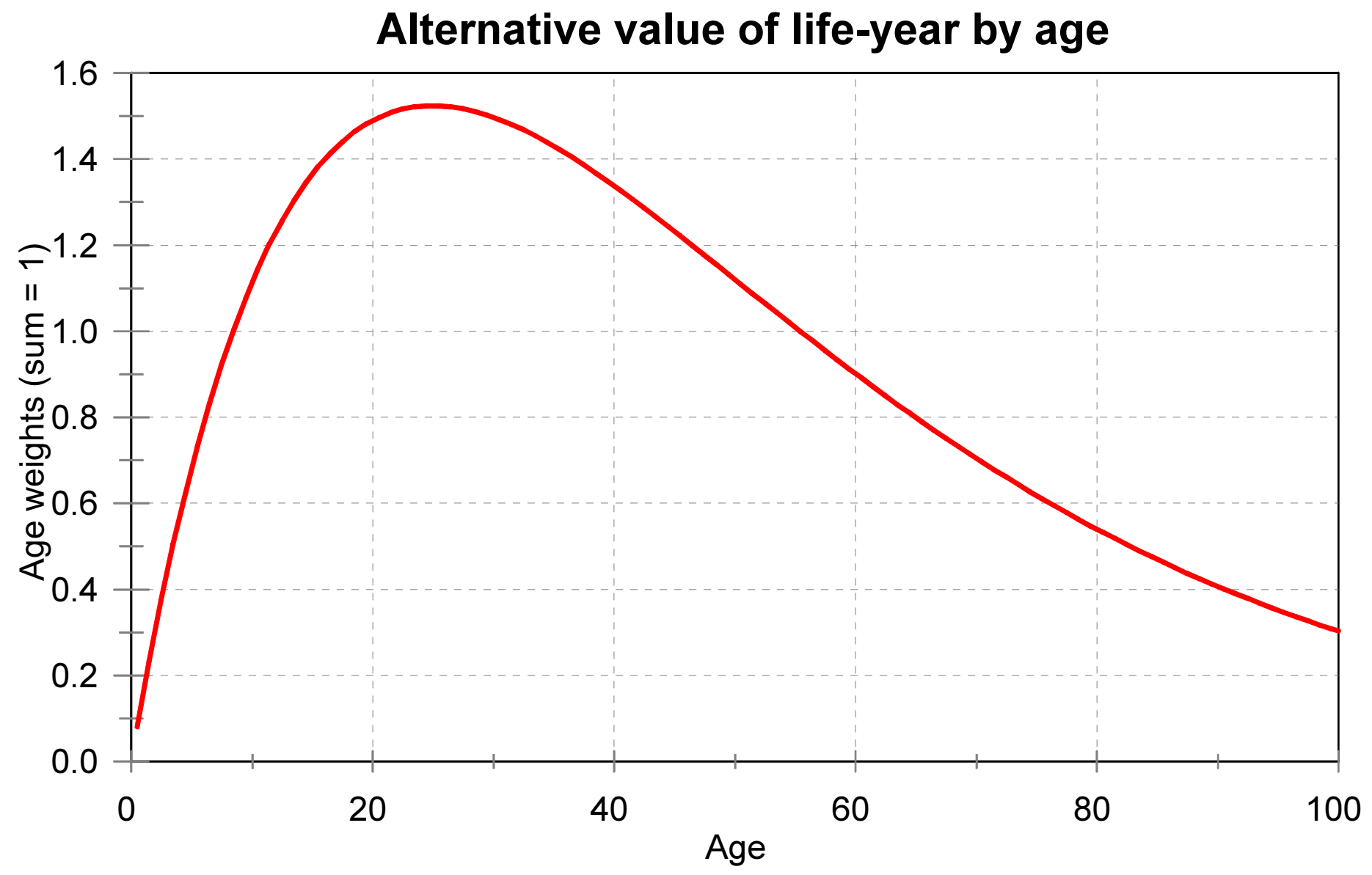


Figure 8

Weighted Life Expectancy for Different Discount Rates and Weighting Factors

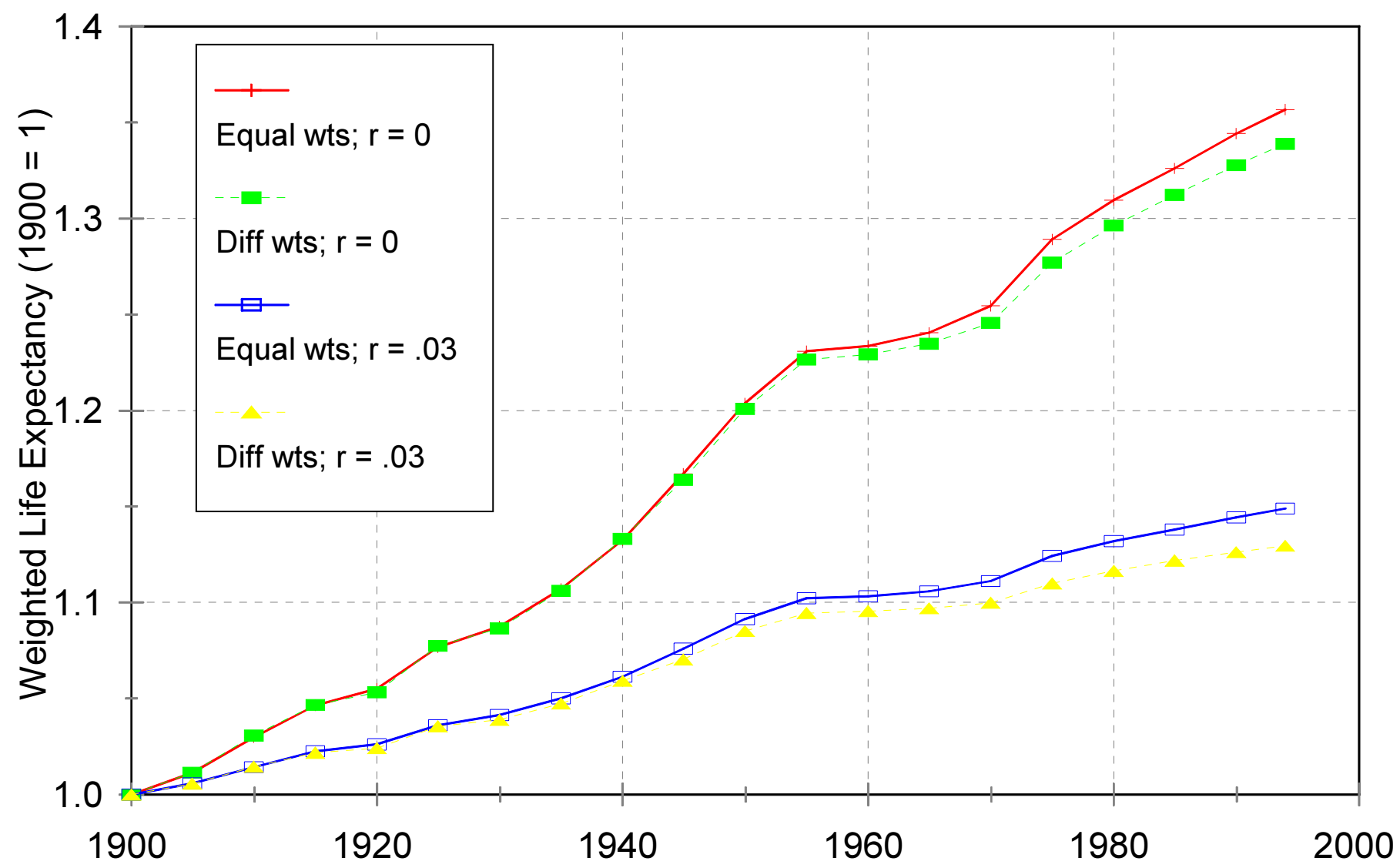


Figure 9

Change in Weighted Life Expectancy for Different Discount Rates and Weighting Factors

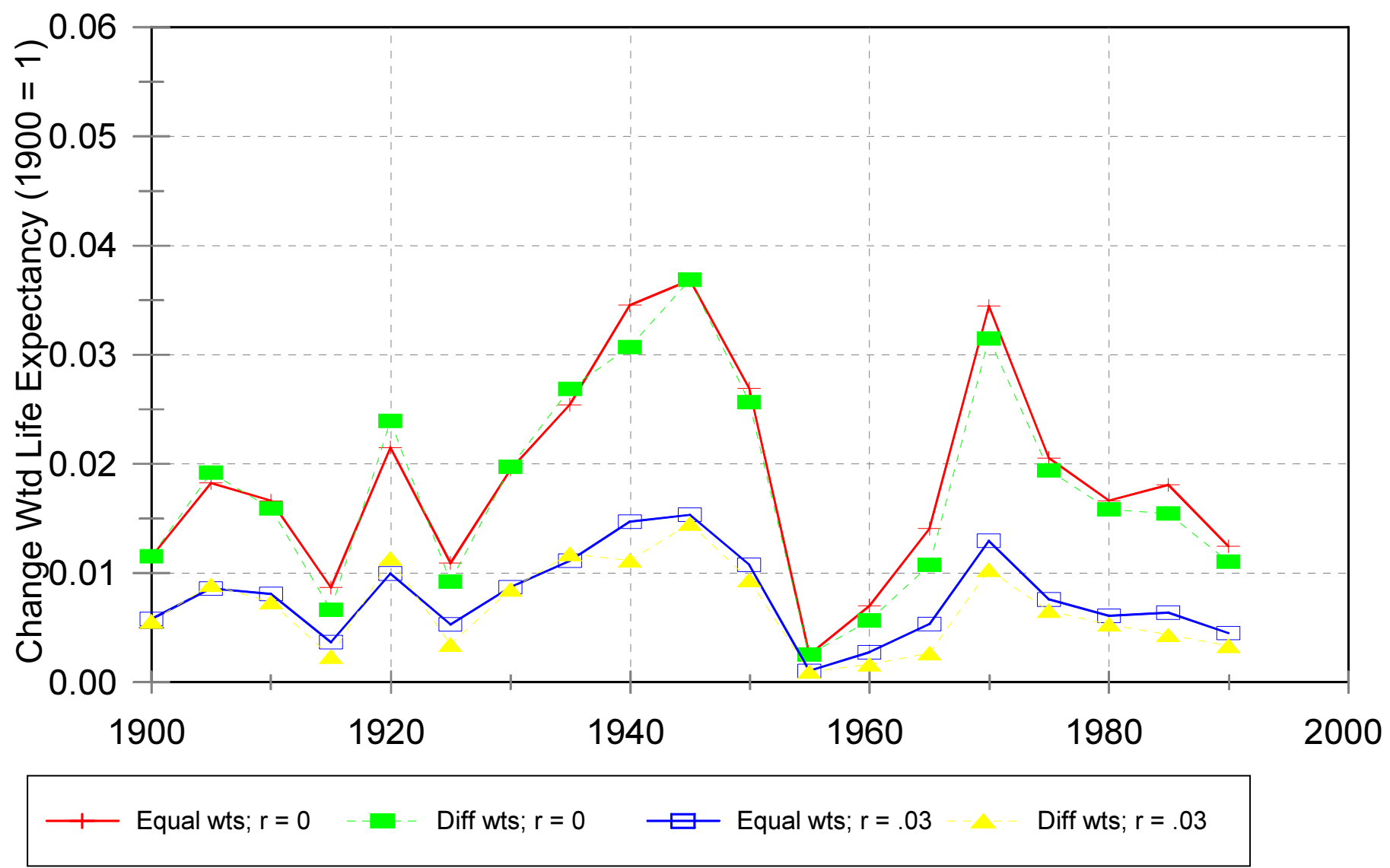

